\title{
Construction of the sub-level website of a newly established college Cite Shang Luo Academy as an example
}

\author{
Bin Li \\ Arts Department of Shang Luo University Shang Luo University, Shang Luo 726000, China. \\ Lib9308@163.com
}

Keywords: ASP technology; web site templates; image database; test.

\begin{abstract}
According to the two website construction in newly built undergraduate universities lack of autonomy, based on the ASP web site on the basis of understanding, from the Shangluo College School of art website template construction, namely: the whole frame set, site before and after the set, image database connection file, and security, the server part of the whole test and perfect, just around the college website construction, website construction of two new undergraduate colleges play an exploratory role.
\end{abstract}

\section{Introduction}

In the development of modern education information technology today, the website has become an important window of foreign propaganda image. At present, most colleges and universities website construction has a certain foundation, but the initiative in their own websites still cannot meet the requirements, the lack of personnel and technical support, some network services to provide [1]. In this case, especially the deepening of the new undergraduate colleges cannot offer timely and relevant information to the school teachers and students and society through their own network. In order to promote the construction of sub-level site and operation of new undergraduate colleges, independent development of the construction site, this dissertation develops from two level ASP technology overview, sub-level site template construction, IIS server test and further improvement in the overall construction ideas.

\section{An overview of ASP Technology}

The Microsoft Corp released the ASP, called as the Active Server Page, which means the active server page script running environment, the relationship between the interactions with customers and establish ", is a very typical server end webpage design technology.

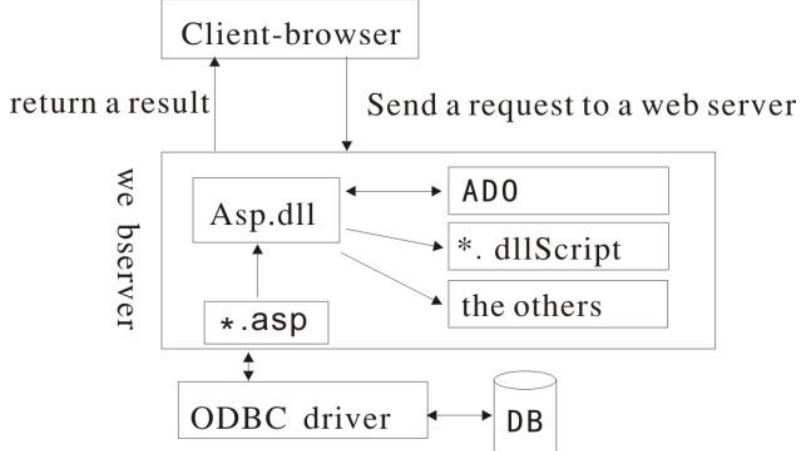

Fig. 1 The basic principle of ASP website technology

The realization of the construction site in ASP Technology. The application of ASP is the ASP page and the ActiveX component of the set [2]. The site environment to achieve as shown in figure 1 . When the user opens the ASP website, it is the client's browser, and sent to the web server through the ASP engine, quick start ODBC driver on DB database, open the web page that is to return a result, 
when the server returns the result to the client browser, said the end of a work flow. To clear the Web site in the file or folder for the application of the website starting point directory, whenever the user define applications, will use the Internet Services Manager Web site, and become part of the application, until you find another starting point directory. It briefly summed up as follows: the client browser as the beginning, followed by the server, the ASP script, the driver, the database [3].

For the technical advantages of ASP site in newly built undergraduate universities. When including a subsection you must use, for its heading, small letters, 12pt, left justified, bold, Times New Roman as here.

Before ASP was born in 1996, the website construction of static Webpage more generally, and the site if there are some changes, you need to re-design of each page of the source code. Since the birth of ASP, has been widely applied to the construction site. The current PHP technology has replaced the ASP technology advantages, but in the construction of two level Web technology requirements of the newly built undergraduate course colleges and universities, and has a certain application prospect. The technical features of ASP are as follows:

First of all, the ASP server-side scripting to write simple grammar. ASP syntax in the form of $<$ ! -\# includefile = "conn ASP" - > form contained in the HTML code, only need to put ASP technology in the server component, the built-in code package will be able to complete the operation steps, the interaction between Web pages, and can be added with Java, HTML, C and other languages mixed programming in server script language.

Secondly, the ASP technology of virtual operating environment to establish convenient. ASP technology in virtual environment based on IIS servers are often implemented. The start - control panel - Administrative Tools - Internet information server - local connection - your default web site to modify the site path, and then enter the http://localhost or http://127.0.0.1 to view the site local connections in the browser. Can also through some small plug-in, such as a small whirlwind AspWebServer1.0.exe virtual ASP campus website, simply modify.

\section{Based on the ASP basis, to create the Art College of Shangluo College website template}

In the website construction institute two level of art college, first of all do a reality check on the website, the actual survey here is of similar colleges and universities campus website construction level two surveys, but also combined with the actual situation of College of art, make a overall site plan, as shown in Figure 2 is the two website construction Hierarchical Planning Institute of the arts. Should from the clear structure, exquisite appearance in the website construction of College of art, visitor's happy and easy acceptance and other aspects to consider, so more conducive to enhance the image of the site. In the special school of art, the art exhibitions, performances, dance and other art activities do a column on the home page, because art is the art of news highlights, intuitive and strong, distinctive features, content features, placed in the home is the eye position, become the first visitors to open a web page time will be able to see the contents.

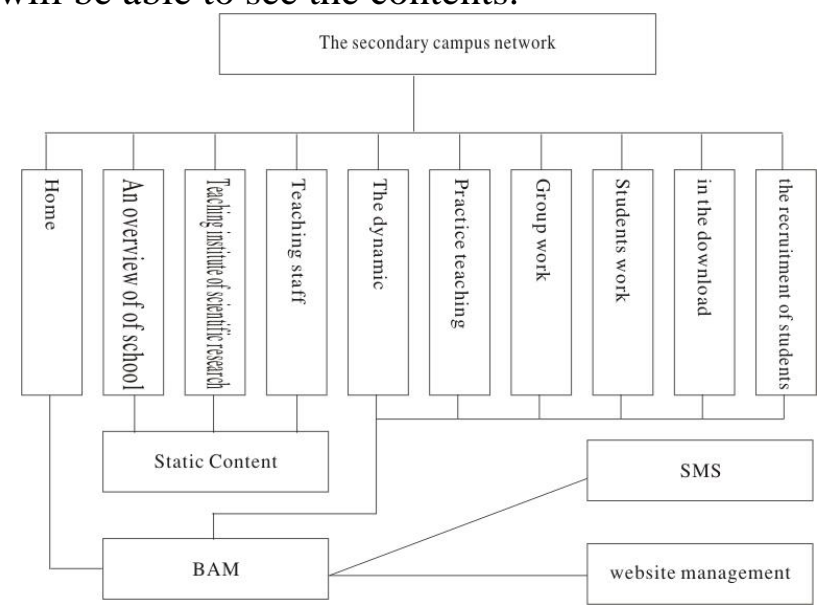

Fig. 2 Art College website construction structure 
Create a school of art website. According to the particularity of the professional art College of Shangluo College, in the construction site more consideration from the artistic atmosphere, which should be reflected from the Art Institute website Index.asp. The navigation bar in Index.asp plays a key role in the navigation. Combined with the navigation bar set Art Institute website, through the analysis of similar college's art college web site, in the navigation bar settings: home, an overview of of school, teaching institute of scientific research, the dynamic, teaching staff, practice teaching, group work, students work, in the download, the recruitment of student's employment ten navigation key words. Set on the home page section, respectively from the photo news, news, announcements, and art activities, and teachers highlight the characteristics of the arts website on plate, and appropriate to join *. SWF dynamic images, rich page effect. Home page is a sign of a web site and the soul, to maintain the appearance of the site consistency, shall establish unified CSS styles and also pay attention to the organic combination between the Flash and the static HTML files [4].Shang Luo College College art background management includes user management and site management two parts [5]. User management is from the website backstage to edit users, which is divided into 'add administrators' and 'remove administrator', and 'the administrator to set permissions'. Site management includes the addition of interface management, content management, program management, and other functions of user management which is mainly used to generate site. The composition of the module is shown as in figure 3.

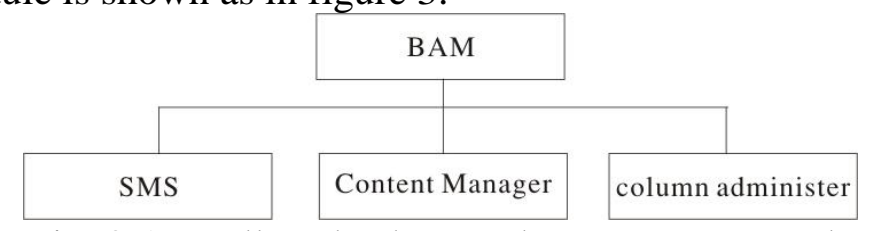

Fig. 3 Art college background management mode

Create professional art college "image database". The 21st century has become worthy of the name "map reading age" [6]. According to the professional characteristics of Art College, its website should consider "images" website. So set up their own reasonable "image database" with the characteristics, and before the image databases, constructors should classify collected images information on the demand of the navigation module. It is shown in figure 4 that art college faculty classification of image collection:

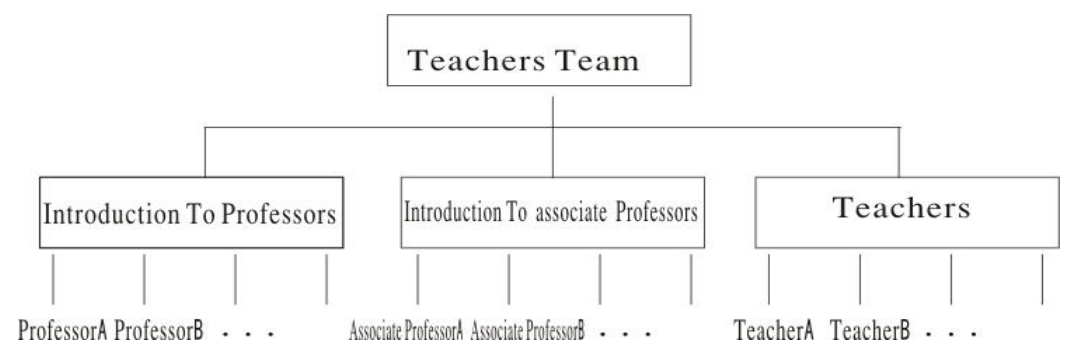

Fig. 4 Art college faculty classification of image collection

Create a connection about ASP database of Art College's website, and pay attention to the security of the database.It is the database connection by conn. Asp file.

$<\%$

Dim conn, connstr

Connstr="DRIVER $=$ Microsoft Access Driver (* . mdb); "

$\mathrm{DBQ}=$ "+server.mappath(“*.mdb")+"

Set Conn= Server. CreateObject(“ADODB. Connection”)

conn. Open connstr

$\%>$

This code on the web page has high utilization ratio of database operations [7]. College of art website ASP connection file should also pay attention to the security of the database. Access database in the form of files saved and encryption is relatively simple, so security is not high, but shall ensure that the file will not be downloaded or database to save all of the information that may leak. Also the safety of the image database to add some protective measures: (1) create unconventional Access 
database name, and store it in a multilayer directory, so it is not easy to be found by invaders; (2). Use the ODBC data source, and open the data source in the following way: in the program ONERR ORRESU MENEXTconn. Open the "ODBC - DSNName"; [8] (3). The database to the extension of the forced. Asp or. Asa format; (4). The database name begins with "\#", insert OLE object in the table, etc.

\section{To run the test of art college's website template and perfect it}

Test, the main job, is to find errors existing in the system. The fundamental goal of the test phase is to find errors as many as possible and eliminate them existing in software [9]. Art institute of secondary website template revised, you need run the test it on a suitable ASP website running environment IIS server ---- this phase is very important. On the one hand, test whether it is OK in the school running environment IIS running on the server, on the other hand, supervise the web site overall structure is normal. Here well-functioning usually refers to whether there are any code errors, such as usually conn. Asp path connection error-----typically the path should be a relative path, namely: Data = "" \& SitePath \&" DataBase / \# *. MDB ". Web site overall structure here is normal, according to the general inspection picture, logo, website framework, the rationality of the navigation classification, etc.

After ASP template test finishes, you can upload perfect news, teacher introduction, art activities and other columns category. At the art institute of perfect work, a template should not only consider whole school site connectivity to each other, but also coordination to keep clear subject, characteristic, style, etc.

\section{Summary}

Secondary network construction of newly-built undergraduate universities and colleges is a strong practice application technology; the overall site construction needs starting from the demand of the website construction, highlighting a reasonable site framework model. Further, on the basis of further classification designed, college professional nature should be highlighted with the front desk and image database. To create the site link based on the ASP file, one also should consider database security finally through the test operation to perfect and further enrich content of the site.

\section{References}

[1] Yanwen Liu, Xia Zhou. Based on the technology of ASP + ACCESS in University website construction [J]. Science and technology information (academic). 2007(30):212.

[2] Yonghong Duan, Chunhai li. Based on ASP website construction. Development and utilization of computer [J].2007(13):29.

[3] Zhao Ban.The analysis of application of ASP technology in the website construction [J].silicon valley. 2012(12):20.

[4] Lifeng Wang, Meng Sun. Based on the technology of ASP dynamic website construction in Secondary colleges site [J]. Forestry Education in China. (3): 2007-47 to 49.

[5] Jianzhong Diao, Zunde Chen. The design and implementation of departmental website in colleges [J].Information Technology.2008, 32(7).

[6] Yabin Li.The Photo Website Construction of Xi'an University of Science and Technology Based on the ASP [D]. Xi 'an university of science and technology.2013:1.

[7] Xiaoping Wang Jun Zhong. Internet development technology based on ASP [M]. the communications periodicals of the posts and telecommunications press.2006(2):129-145.

[8] Hong Xu.Security analysis and protection of ASP web database [J]. Journal of huaiyin institute of technology. 2004(13)5:39-40.

[9] Changqin Yan, Jiya Huang, LiJuan Qi. ASP.NET access SQL database image method [J].Science \& Technology information.2011, 15: 20. 